\title{
The Impedance Cardiography Technique in Medical Diagnosis
}

Type of article: Review

\author{
Hadjer Benabdallah ${ }^{1}$, Dr Salim Kerai ${ }^{2}$ \\ 1. Ph.D Student Biomedical Engineering, Department of Biomedical Engineering, \\ Biomedical Engineering Laboratory, Faculty of Technology, University of Tlemcen, \\ Algeria. \\ 2. Department of Biomedical Engineering, Faculty of Technology, University of Tlemcen, \\ Algeria.
}

\begin{abstract}
Background: Thoracic Electrical Bioimpedance (TEB) Technology is sometimes called Impedance Cardiography (ICG). The Impedance Cardiography emerged in 1940. Studies of this technique are applied to detect the cardiovascular diseases by measuring hemodynamic parameters using skin electrodes contact by injecting a low amplitude alternating signal. This article aims to review the various studies based on this signal type and to present the multiple methods used for the treatment and to have a correct analysis.

Methods: This paper is based on several researches made in recent years published in Science Direct, Google Scholar, and PubMed...etc. The ICG technique consists of applying an electric field longitudinally across a segment of the thorax with an amplitude in mean, high frequency and low amplitude current. To analyze the ICG signal denoising is necessary; therefore, multiple filters are proposed, and the Discrete Wavelet Transform (DWT) denoising is also used.

Results: The ICG is considered advantageous compared to other invasive conventional techniques; it gives a good correlation, and solves Doppler ultrasound and Thermodilution problems. According to the studies, the Daubechies wavelet family $(\mathrm{db} 8)$ is the best DWT to eliminate noises. There are several algorithms for the signal characteristic point's detection.

Conclusion: For cardiovascular disease diagnosis and monitoring, the non-invasive ICG technique comes to solve the complexity problem for measurement and analyzing heart diseases based on the thoracic electrical impedance change assessment that is due to blood velocity and resistivity changes (blood volume changes) in order to estimate several hemodynamic parameters.
\end{abstract}

Keywords: ICG, cardiovascular disease, hemodynamic parameters, automatic diagnosis and monitoring, correct analysis.

Corresponding author: Hadjer Benabdallah, Department of Biomedical Engineering, Biomedical Engineering

Laboratory, Faculty of Technology, University of Tlemcen, Algeria Email: hadjerbenabdallah@gmail.com

Received: June 25, 2018, Accepted: September 02, 2018, English editing: 28 September, 2018,Published: 30 September, 2018. Screened by iThenticate.@2017-2018 KNOWLEDGE KINGDOM PUBLISHING.

\section{Introduction}

Transthoracic electrical bioimpedance cardiography or, simply, impedance cardiography (ICG) or cardiac bioimpedance $[1,2]$, is based on a theoretical model 
of the thorax. This technique is non-invasive, simple, reliable, safe, painless, low cost, fast and, secure with no danger to the subject which measures in over time the thoracic blood volume and blood velocity variation at the aorta level due to impedance changes in each cycle. It is used in order to extract some hemodynamic parameters that help in the cardiovascular diseases diagnosis [3] for cardiac monitoring whether ambulatory or continuous long-term in intensive care units (ICU). The ICG method is considered as an alternative technique to thermodilution [4] and it is a more advantageous technique than the conventional invasive methods. Kubicek et al. [60] developed the four-electrode method for measuring cardiac impedance [5].

The ICG signal can be measured by systems like BioZ, Niccomo, Osypka and Analogic [6] that calculate the SV ejection volume, CardioScreen 2000, and CardioScreen 1000 [7,8].

Studies using the ICG technique are realized for patients with congestive heart failure, with pacemakers, patients requiring fluid management, and with other conditions [9].

Inner electrodes measure the base thoracic impedance $\left(\mathrm{Z}_{0}\right)$ during the diastole considered constant for a patient at about $25 \Omega$, for a man from 20 to $33 \Omega$ and a woman from 27 to $48 \Omega$, [10].Pulsatile impedance/time changes $(d Z / d t), \Delta z$ and ECG signals allow the extraction of hemodynamic parameters for the non-invasive diagnosis of the heart and cardiac circulation to measure: (1)the stroke volume SV; (2) the cardiac output CO; (3) the stroke volume index (SV/SVI); (4) the cardiac index $(\mathrm{CO} / \mathrm{CI}) ;(5)$ the left ventricular ejection time (LVET);(6) the preejection period (PEP); and (7) the heart rate (HR) among others.

Studies of new methods of exploration and medical treatments such as Impedance Cardiography, or ICG, emerged in 1940. In the same year, the National Administration of Aeronautics and Space, (NASA) began the research of the thoracic electrical bio-impedance in 1960 [11, 12] with the ICG heart index record in a continuous, easy, non-invasive and cheaper way. The use of this technique was recognized by the scientific and medical communities [13]. It has been a research object since 1960, when the first test was done. In 1966 [14] the $1^{\text {st }}$ impedance cardiography monitoring device (thoracic electrical bio-impedance) was invented. In the same year, Kubicek [5] replaced the notion of first derivative $d Z / d t$ usable in the ICG method, representing the rate of the impedance variation. He tested a systolic ejection volume (SV) equation according to the bio-impedance [15]. To measure cardiac impedance, Kubicek et al. [60] developed the four-electrode method [5]. In 1981, Smarek developed a new equation in hemodynamic based on variations in thoracic impedance [12]. In the same year, Granerus, and Elg [16] used this signal for the left ventricular ejection volume computation, Kubicek [5] made an electrode location to estimate the ejection volume, and Sramek [17] used 8 electrodes to solve the problem of band electrodes to estimate ejection volume too. The 8 electrodes were placed on the biggest part of the thorax, i.e. along the frontal plane [18].

In this paper, the ICG signal measurement, its shape, and the different studies carried out on this signal type are presented, as well as its characteristics which make it possible to calculate hemodynamic parameters for the cardiovascular diseases' diagnosis. 


\section{THE ICG SIGNAL}

\subsection{ICG measurements}

The ICG measurement is done by injecting a low amplitude alternating signal from $0.2 \mathrm{~mA}$ to $5 \mathrm{~mA}$ and low frequency across the current electrodes in a frequency range of $50 \mathrm{kHz}$ to $100 \mathrm{kHz}$ [19] and for the voltage recovery with the fourelectrode method uses four-band electrodes [20] or 8 spot electrodes like standard ECG electrodes. The first pair of electrodes is placed at the beginning of the thorax and the second one at the end of the thorax (the level of the xiphoid process) [21] where the outer electrodes inject the current and the inner electrodes measure the potential (the sensing electrodes) (Fig.1).

The measurement is based on the skin electrodes contact that generates impedance. In order to eliminate it, the application of pre-gelled highly conductive electrodes is required [11].Furthermore, the appearance of electrode-electrolyte impedance can be greater than the impedance tested especially at low frequencies, which are too unstable and unpredictable to think about the measurement.

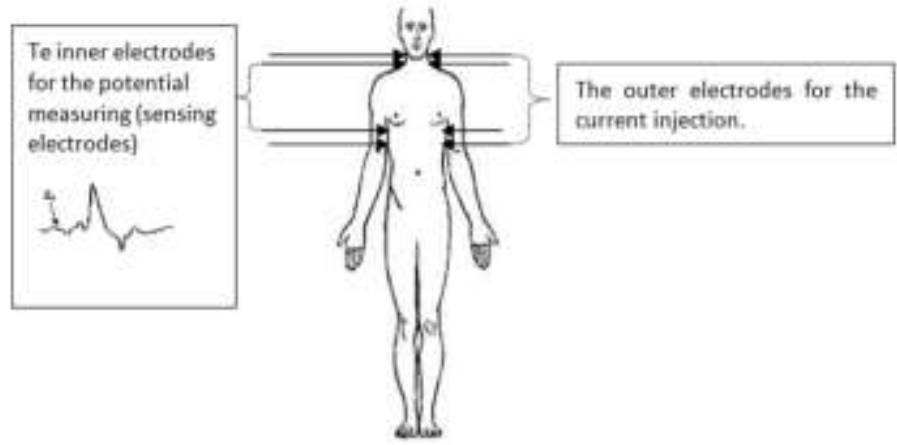

Fig.1. The location of the 8 ICG electrodes on the human body.

\subsection{The theory of hemodynamic parameters determination}

\section{a. Stroke volume}

To measure systolic time intervals based on the bioimpedance changes in the thorax, an alternating electric current is applying. According to Kubicek [5], the thoracic impedance variations are due to the aorta impedance changes which are induced by the passage of the systolic wave. An aorta segment is considered cylindrical, and its impedance formula is as follows:

where

$$
Z=\frac{\rho L^{2}}{V} \text {, }
$$

$\rho:$ is the specific static resistance of blood;

$L:$ is the height of the cylinder that presents the segment of the aorta; and

$V:$ is the variation of blood volume in the vessel.

When the ventricular ejection $d Z / d t$ represents the peaks in the acceleration time domain and $(d Z / d t)_{\max }$ is the variation of the trans-brachial specific resistance of the blood $(\Omega \mathrm{s}-2)$ due to the blood velocity variation, which represents a maximum variation rate of the aortic volume variation, as follows [22]:

$$
\left(\frac{d Z(t)}{d t}\right)_{\max }=\frac{L^{2}}{V}\left(\frac{d \rho(t)}{d t}\right)_{\max }
$$


The systolic ejection volume expressed in ( $\mathrm{mL} /$ beat), which is the product of the systolic volume and the heart rate, serves to estimate the heart health state and extract parameters considering relevant in the diagnosis as the ejection fraction, and it determines the $\mathrm{CO}$ cardiac output (approximately $70 \mathrm{~mL} /$ beat for a healthy adult subject). The stroke volume equation is: SV=EDV-ESV

With

ESV as the: end-systolic volume for a ventricle of one person: ventricle blood at the end of a beat; and

EDV as the: end-diastolic volume for a ventricle of one person: blood before the beat.

Due to the use of the technique of the impedance, the formulas for the SV are the following ones [8] [21] [24]:

According to Nyboer [24], the volume changes in the thorax due to the impedance variation is:

$$
d V_{b}=-\rho_{b} \frac{L^{2}}{Z_{\mathrm{o}}^{2}} d Z \text { or } S V=[\rho] \times[L / Z o] 2 \times \Delta Z
$$

According to Kubicek [5], the equation for the systolic ejection volume depending to the thoracic impedance variation is as follows:

$$
S V=\rho_{b}\left(L \mid Z_{\mathrm{o}}\right)^{2}(d Z \mid d t)_{\max } L V E T \text {. }
$$

As stated by Sramek [17], the systolic ejection volume equation depending on the thoracic impedance variation is:

where

$$
S V=\frac{(0.17 H)^{3}}{4.25} \frac{1}{Z_{\mathrm{o}}}\left(\frac{d z}{d t}\right)_{\max } L V E T
$$

$\rho$ : is a constant specific of the resistivity of blood and variable to person from another person ;

$\rho_{b}$ : is the static specific resistance of blood $\Omega(\mathrm{cm})=135 \Omega \mathrm{cm}$ for $\mathrm{SV}{ }_{\mathrm{k}}$ (QUAIL et al. 1981) [23];

$L:$ is the transthoracic length ;

$Z o:$ is the basic impedance of the thorax $(\Omega)$; and

LVET: is the left ventricular ejection time.

According to D.P. Bernstein et al. [25], and Sramek [17], the equation of systolic ejection volume SV depending on the thoracic impedance variation and Bernstein correction factor is as follows[15][25]:

$$
S V=\sigma \frac{(0.17 H)^{3}}{4.25} \frac{1}{Z_{\mathrm{o}}}\left(\frac{d z}{d t}\right)_{\max } L V E T \text { with } \sigma=\sqrt{\text { BMIpatient } / 24} \text {, }
$$

so that the other formulas have been developed and with.

$B M I$ as the body mass index;

$\delta$ is the Bernstein Correction Factor;

24 is the ideal BMI value assumed by Bernstein $\left(\mathrm{kg} . \mathrm{m}^{-2}\right)$;

$P$ : is the weight of the patient in $(\mathrm{kg})$; and $\mathrm{H}$ is its size in $(\mathrm{m})$. 
The new Bernstein equation $\mathrm{N}: S V=V_{c} \sqrt{\frac{1}{z_{\mathrm{o}}}\left(\frac{d z}{d t}\right)} \max L V E T$,

where $V_{c}$ is the intrathoracic blood volume $(\mathrm{mL})$.

\section{b. The cardiac output}

The cardiac output $(\mathrm{CO})$ expressed as $(\mathrm{L} / \mathrm{min}$ or $\mathrm{mL} / \mathrm{min})$ is the total amount of blood ejected by the left ventricle into the systemic circulation at each heart beat multiplied by the heart rate in one minute, it is approximately $5.6 \mathrm{~L} / \mathrm{min}$ for the man and 4.9L / min for the woman [8]. The equations are following:

$C O=$ stroke volume $\times$ heart rate; and

$C I=$ cardiac output/body surface area.

\subsection{ICG signal characteristics}

From the signal ICG (Fig.2), the characteristic points are extracted which allow the calculation of the desired indices [2] [26] (Fig.3), as following:

(1) The $A$ wave seems to coincide with the $P$ wave of the ECG.

(2) The point $B$ : corresponds to the opening of the aortic and pulmonary valves. According to Lababidi et al. [27] the point $B=15 \%$ de $(d Z / d t)_{\max }$. It is the point where $\frac{d^{2} Z}{d t^{2} \text { gauche }}<\frac{d^{2} Z}{d t^{2} \text { droite }}$.

(3) The point $C$ : corresponds to the maximum peak of the $d Z / d t$ (ICG) signal on a heartbeat. It is the blood ejection rate by the ventricles, which corresponds to the ventricular contraction.

(4) The point $X$ : is the lowest point after peak $C$ and is associated with the closure of the aortic valve.

(5) The point $Y$ : corresponds to the closure of the pulmonary valve.

(6) The wave $O$ occurs during the diastole (the passive blood passage between the atriums and the ventricles), its peak is the moment of the mitral valve opening.

Due to the Pan-Tompkins algorithm, the peak $C$ is detected [28]. The point-bypoint methods detect the points $B$ and $X$ from the points $C$, as the manner of the point $Q$ detected from the point $R$ on the ECG. Once the points $B, C$ and $X$ have been detected, the set of cardiac indices is computable by the formulas. In 1986, Donovan et al. showed that if the ratio between peak $O$ and $C(O / C>0.3)$ is greater than 0.3 the patient has a pulmonary pathology [2].

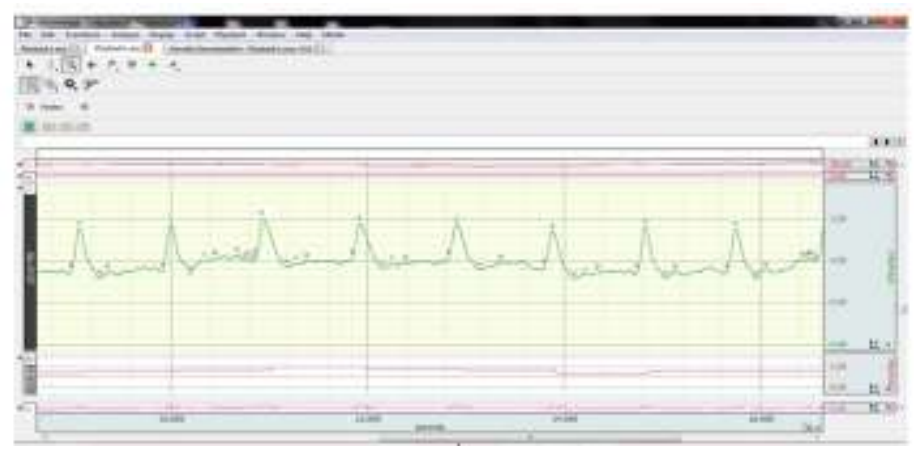


Fig.2.The shape of the ICG signal recorded on the AcqKnowledge 5.0 software.

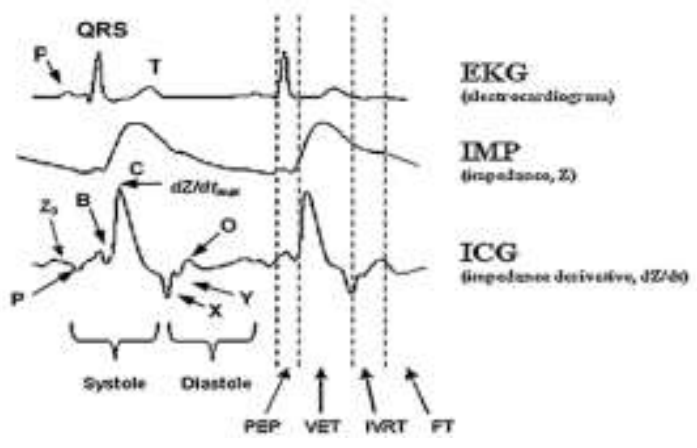

Fig.3.The composition of the ICG signal, where $Z_{0}$ : baseline impedance; $A$ : atrial wave; $B$ : aortic valve opening; $C$ : maximum aortic flow $(d Z / d t)_{\max } ; X$ : aortic valve closing; $Y$ : pulmonic valve closing; $O$ : mitral valve opening; $P E P$ : pre-ejection period; $V E T$ : ventricular ejection time; IVRT: isovolumic relaxation time; and $F T$ : ventricular filling time [11].

\section{THE ICG ANALYSIS}

ICG is a diagnostic technique for cardiovascular disease. It is used for the measurement of hemodynamic parameters that are wrong due to noise which reaches the signal and, make the signal analysis inaccurate and very difficult finding the correct diagnosis. The solution is to use the wavelets to denoise the signal.

The correct segmentation of signals makes a problem in the biomedical engineering field. That is why many studies have been done to obtain a better approach to signal segmentation and especially of the highly variable signals. These methods allow creating an adequate model for a subject.

A method of segmenting heartbeats for cardiovascular signals is based on the following model [29]:

$$
x(t)=A \sin \left(2 \pi f_{0} t\right)+B \cos \left(2 \pi f_{0} t\right)+C,
$$

composed of 4 parameters developed by Pinheiro Eduardo et al. in 2011[30]. It is based on a sliding power window without the need for a hypothetical formula on the shape of patient's heart rate or a reference signal to synchronize the segmentation points. Its purpose is to transform the cardiac signal and obtain the fundamental heart rate oscillation frequency. They used the ICG signal. This kind of test is done on a wheelchair because of the artefacts due to vibration, such as movement as well as when speaking [31]. Artefact types such as high amplitude pulses or weak base variations cause problems of reproducibility and repeatability [32] that are eliminated through heuristic procedures [33, 34]. This method segments highly variable signals and, makes it possible to create a suitable model for a subject, which is based on wavelet filtering and peaks detection [33, 35].

In order to study the ICG signal, Ermishkin relied on two hypotheses: the first consists of heart geometry variation and that the vessels surrounded in the preejection phase, the second is the expansion of the aorta and the adjacent arteries. He used a mathematical model based on a process summation effect with the $d Z / d t$ 
waveform and the associated ICG parameters, the first of which refer to the $\mathrm{WpE}$ pre-injection wave and the second referring to the ejection wave $W E j$ where

$$
\Delta Z=(W p E+W E j)
$$

An asymmetric bell-shaped function is whose. Its form is as follows:

$$
W(A, b, c, t)=A \cdot e^{-c t} \cdot t^{b}
$$

He used the first and the second derivatives as well as time relations between $t_{0}$, $t_{\min }$, and $t_{\max }$ for the characteristic points detection of the signal ICG as the maximum of the wave $C$ which corresponds to $(d W / d t)_{\max }$ and the point $B$ which corresponds to the second derivative [36].To denoise the signal, in 2016 Ridha Ben Salah [26] tested 3 types of methods described below:(1) The term Discrete Wavelet Transform (DWT) [37] actually encompass several types of Wavelets (bases), e.g., the Haar, Daubechies (db2, db4, db6, and db8), Symlet (sym2, sym4, sym6, sym8), and the Coiflet (coif2, coif3, coif4, coif5) wavelets, the DWT equation [38] is as follows:

$$
\mathrm{X}[a, b]=\sum_{\mathrm{n}=-\infty}^{+\infty} \mathrm{X}[\mathrm{n}] \psi_{\mathrm{a}, \mathrm{b}}[n] \text { with } \psi_{\mathrm{a}, \mathrm{b}}[n]=\frac{1}{\sqrt{\mathrm{a}}} \times \psi\left[\frac{\mathrm{n}-\mathrm{b}}{\mathrm{a}}\right],
$$

where $a$, and $b$ are the parameters of the wavelet location, $x[n]$ are the coefficients (scaling factors), and $\psi$ (.) is the mother wavelet. (2) The Savitzky-Golay filter [39], and (3) The median filter.

An adaptive filtering technique based on the least mean squares (LMS) has been proposed in [40, 41]. Meyer wavelet-based denoising was also used for the ICG signal $[42,43]$. Ridha Ben Salah used each denoising method after measuring the $C$ wave, which is considered the most characteristic wave for each type, and then calculates the difference between the $C$ of the original signal and the $C$ of the filtered signal. If the difference is smaller, the method used is the more suitable for signal denoising ICG. According to the studies, the Daubechies wavelet family $(\mathrm{db8})$ is the best DWT to reduce noise, it gives a better separation between the noise and the signal. It allows to determine the cardiovascular parameters and to diagnose the cardiovascular diseases [26].

The study that comes next by Ben Salah et al. has an accuracy rate of $95.40 \%$. They worked with the normal and abnormal ICG signal for the cardiovascular diseases detection, using a CAD system (Computer Aided Diagnosis system) for that. This study based on (1) Temporal, (2) spectral features, and (3) classification with the linear discriminant method [44]. The ICG technique solves the Doppler ultrasound problem which is used to examine cardiovascular diseases as valve heart disease (VHD) but it is expensive, and requires expertise to perform it and discontinuity. In order to analyze the ICG signal, in 2017, Souhir Chabchoub [45] followed a methodology that has an accuracy rate of $98.94 \%$. The steps are as follows: (1) denoise the ICG signal by the Daubechies wavelet family, (2) 
segmentation where the signals will be segmented into heartbeats, (3) linear prediction method (LP), (4) temporal and time-frequency characteristics extraction, and (5) classification with support vector machine (SVM) and K-nearest neighbour (KNN). The ICG was used to detect heart failure [46, 47], myocardial infarction [48], and mitral insufficiency [49].

\section{Discussion}

\subsection{The evaluation of the ICG technique}

The electrical impedance has parameters that can be used for the diagnosis and monitoring of the pathological condition of the patient's tissues; it is measured invasively including the following methods: (1) Direct Fick: to measure mixed oxygen concentrations of venous blood in order to estimate cardiac output. (2) Indirect Fick: similar to the direct Fick method, but its specificity is that it uses pulse oximetry to evaluate the arterial oxygen content. (3) Thermodilution [50, 51]: the temperature changes of a solution injected through the right atrial chamber that is measured to estimate cardiac output, was distinguished by its wide measurement variability especially in clinical practice. (4) Dye dilution: It seems like the technique of thermodilition, based on the dye that is injected through the pulmonary artery and it is the peripheral site that will measure its concentration. (5) Radionuclide angiography or ventriculography [9, 52]: allows estimating the cardiac output by applying the dynamic sampling radioactive counts of the left ventricle technique.

To evaluate the accuracy of the ICG technique, the bioimpedance correlation coefficient is calculated and compared to other techniques such as thermodilution (TD), it is between -0.01 and 0.97 . It has an accuracy comparable to conventional invasive methods, and portability, it is easier to use, suitable for continuous monitoring, and at low cost for many applications in cardiology [13]. The results of the measurement are influenced by several errors such as wave positioning, patients' weight, and pulmonary oedema [9].

Studies [22] have been done to measure the reliability of non-invasive bioimpedance techniques by measuring different hemodynamic parameters that are already calculated by invasive techniques. They have chosen specific populations for each study. Some research results are as following:

\begin{tabular}{|l|l|}
\hline Deepak et al.[54] & $\begin{array}{l}\text { TEB vs Fick } \\
\text { A correlation rate }=0.9\end{array}$ \\
\hline Sharma et al.[53] & $\begin{array}{l}\text { TEB vs Thermodilution TD } \\
\text { Results: good correlation } \\
\text { Bland Altman with error }=19.3 \%\end{array}$ \\
\hline $\begin{array}{l}\text { Belardinelli } \\
\text { al. }[56]\end{array}$ & $\begin{array}{l}\text { ICG vs TD } \\
\text { patients in the rest and the effort } \\
\text { A correlation rate }=0.89 .\end{array}$ \\
\hline Cotter et al. [55] & $\begin{array}{l}\text { TD vs ICG in a population of patients } \\
\text { with acute heart failure. } \\
\text { Results: good correlation }\end{array}$ \\
\hline
\end{tabular}




\begin{tabular}{|l|l|}
\hline Yung GL et al.[57] & $\begin{array}{l}\text { TD vs ICG and Fick } \\
\text { A correlation rate }=0.8\end{array}$ \\
\hline $\begin{array}{l}\text { DeMarzo AP. et } \\
\text { al.[58] }\end{array}$ & $\begin{array}{l}\text { ICG vs Aortic Doppler } \\
\text { The detection of the aortic valve } \\
\text { opening by using of the ICG technique } \\
\text { and aortic Doppler. } \\
\text { A high correlation rate }(\mathrm{r}=0.996) \\
\text { between ICG and Doppler values. }\end{array}$ \\
\hline Faddy.S et al.[13] & $\begin{array}{l}\text { Database contains 27 patients with a } \\
\text { right heart catheterization disease. The } \\
\text { results show a good correlation (r = } \\
\text { 0.91) between thermodilution and TEB } \\
\text { for the measurement of cardiac output } \\
\text { by using the Linear regression } \\
\text { analysis. }\end{array}$ \\
\hline
\end{tabular}

Table1. The comparison of the results from the ICG methods with the invasive methods for hemodynamic parameters.

\subsection{The ICG technique advantages and limitations}

The ICG technique is very useful and advantageous in the medical field because it is non-invasive, flexible, simple, reliable, safe, painless, at low cost, manipulable by a nurse or technician, fast, it ensures the security ( no danger on the subject) and time is saved for the care, it allows to obtain continuous and real-time hemodynamic data measurements as well as the diagnosis of cardiovascular diseases such as mitral insufficiency and heart failure, but it is limited in the field of the valvular heart disease detection [45]. It also provides a better distribution where the noises are minimal, and the electrode-skin surface impedance is low [8]. The ICG method is affected by several changes such as: (1) biological composition, (2) respiration, (3) noise due to movement or equipment, (4) blood circulation, (5) volume blood from the transthoracic region, (6) electrodes emplacement or their contacts with tissue, (7) tissue fluid volume, (8) sweating skin, and (9) myocardial tissue contraction [59].

\section{Conclusion}

Impedance cardiography, or ICG, is a method to obtain the cardiac indexes including cardiac output. This method has many advantages that are noninvasiveness, low cost, and ease of use, but also the possible measurements in continuity. However, it has limitations that prevent its implementation in medical practice especially for patients' with critical cases. Studies are limited, clinical reports on the use of transthoracic electrical bioimpedance cardiography for various clinical indications in reports published from 1991 suggest that this non-invasive method is interesting and could potentially support some of these indications [9]. There are multiple algorithms that are used to process ICG signals and that are not 
universal as well as others that eliminate the noise and deform the signal to prevent its correct analysis [60-63].

This article helps readers to understand the impedance cardiography technique, and its behaviour as well as its analysis and, to know the hemodynamic parameters calculations theory that helps in the diagnosis of cardiovascular diseases and their monitoring. The evaluation of this technique significantly shows the good correlation with invasive techniques which also measure the same parameters.

\title{
6. Conflict of interest statement
}

This article is an advanced version of a presentation at the International Congress on Health Sciences and Medical Technologies 2018 ICHSMT'18.

\section{Authors' biography}

\author{
Hadjer BENABDALLAH, PhD Student \\ Department of Biomedical Engineering, Biomedical Engineering Laboratory, \\ Faculty of Technology, University of Tlemcen, Algeria.
}

\section{Salim KERAI, Doctor}

Department of Biomedical Engineering, Faculty of Technology, University of Tlemcen, Algeria.

\section{Reference}

1.Cinca J., Warren M., Carreno A., Tresanchez M., Armadans L., Gomez P. Solar-Solar J. Changes in myocardial electrical impedance induced by coronary artery occlusion in pics with and without preconditioning: correlation with local ST-segment potential and ventricular arrythmias. Circulation 96(9), 3079-3086 (1997). Available at: https://doi.org/10.1161/01. CIR.96.9.3079

2.Woltjer H.H., Bogaard H.J., de Vries P.M.J.M.The techniqueof impedancecardiography. European HeartJournal18,1396-1403(1997).

https://doi.org/10.1093/oxfordjournals.eurheartj.a015464PMid:9458444

3.Shyu L.Y., Hiang C.Y., Liu C.P., Hu W.C. (2000).Portable impedance cardiography system for real-time noninvasive cardiac output measurement. Journal of medical and biological Engineering,20(4),193-202.

4.Shoemaker, W. C., Wo, C. C., Chan, L., Ramicone, E., Kamel, E. S., Velmahos, G. C., and Belzberg, H. (2001): 'Outcome prediction of emergency patients by noninvasive hemodynamic monitoring', Chest, 120,pp.528537. https://doi.org/10.1378/chest.120.2.528

5.Kubicek, W.G. (1966). Development and evaluation of an impedance cardiac output system. Aerospace Med.,37,1208-1212. PMid:5339656

6.Internet website, the ICG Technology, https://www.physioflow.com/sm_icg_technology.php, visited on 12/06/2018.

7.Internet website, the ICG systems, https://medis.company/cms/index.php?page=icgimpedance-cardiography, visited on 05/05/2018.

8.Bera, T.K. (2014). Bioeletrical impedance methods for noninvasive health monitoring: A review. Journalof medical engineeringhttps://doi.org/10.1155/2014/381251

9.Jordan, H.S., Ioannidis, J.P.A., Goudas, L.C., Chung, M., Kupelnick, B., Miller, K., Terrin, N., Lau J., Thoracic Electrical Bioimpedance [Internet], Rockville (MD): Agency for Healthcare Research and Quality (US); 2002 Nov 27.). 
10.Stevanovic,P., Scepanovic, R.,Radovanovic,D., Bajec, D., Perunovic, R., Stojanovic, D., Stevnovic, D. (2008). Thoracic Electrical Bioimpedance Theory and Clinical Possibilities in Perioperative Medicine, Signa Vitae: journal of intensive care and emergency medicine, 3(suppl.1) 22-27.

11.Summers, R.L., Shoemaker, W.C., Peacock, W.F., Ander, D.S., \& Coleman, T.G. (2003). Bench to bedside: electrophysiologic and clinical principles for noninvasive hemodynamic monitoring using impedance cardiography.Academic emergency medicine,10(6),669-680. https://doi.org/10.1197/aemj.10.6.669 https://doi.org/10.1111/j.1553-2712.2003.tb00054.X PMid:12782531

12.Bayod S., Hermant, A. Les applications de la bioimpédance, Projet DESS, UTC, 98-99, pp 53. 13.Faddy, S., Boland, J. \& Muller, D.W.M. (2003).Accuracy and reliability of non-invasive cardiac output:the future in cardiology?. In Computers in cardiologie,2003(pp.251-253).IEEE. https://doi.org/10.1109/CIC.2003.1291138

14.Shoemaker, W.C., Wo, C.C., Bishop, M.H., Appel, P.L., de Water Van, J.M., Harrington,G.R.\& Patil, R.S. (1994). Multicenter trial of a new thoracic electrical bioimpedance device for cardiac output estimation. Critical care medicine, 22(12),1907-1912.https://doi.org/10.1097/00003246199412000-00004PMid:7988125

15.Tsadok, S. (1999).The historical evolution of bioimpedance. AACN Advanced Critical Care, 10(3),371-384.

16.Granerus, G., \&Elg, R.(1982).Stroke Volume Measurement by Impedance Cardiography Using a Formula Based on the $\Delta \mathrm{z}$ Waveform. Clinical Physics and Physiological Measurement, 3(2),131. https://doi.org/10.1088/0143-0815/3/2/003PMid:6126290

17.Sramek B.B. (1986) BoMed's electrical bioimpedance technology for thoracic applications (NCCOM): Status report, May 1986 Update. Irvine, BoMed Ltd, 1986, 19+2 p.

18.Choudhari, P. \&Panse,M.S. (2013). Measurement of Cardiac Output using Bioimpedance Method. In IJCA Proceedings on International Conference on Communication Technology ICCT(vol.2,pp.28-33).

19.Shih, H., \& Lo, T.C. (1996). Electrochemical impedance spectroscopy for battery research and development. Cortech Corporation. CA, Tech.Rep, 31(9-11).

20.Huysmans, M. C ., Longbottom, C., Bitts, N.B., Los, P., \& Bruce, P.G. (1996). Impedance spectroscopy of teeth with and without approximal caries lesions- an vitro study, Journal of dental research,75(11),1871-1878. https://doi.org/10.1177/00220345960750110901PMid:9003234

21.Malmivuo,P., Malmivuo, J. \& Plonsey, R.(1995). Bioelectromagnetism: Principles and Applications of Bioelectric and Biomagnetic Fields. Oxford University Press, USA. https://doi.org/10.1093/acprof:oso/9780195058239.001.0001PMid:7494216

22.Panse,P.,\&Choudhari,M.S (2013). Measurement of Cardiac Output using Bioimpedance Method. International Journal of Computer Applications, 28-33.

23.Quail, A. W., Traugott, F. M., Porges, W. L., and White, S. W. (1981): 'Thoracic resistivity for stroke volume determination in impedance cardiography', J. Appl. Physiol., SO, pp. 191195.

24.Internet Article, Overview of Impedance Cardiography (ICG), http://impedancecardiography.com/icgover10.html

25.Bernstein, D.P., Lemmens, H.J.M. (2005) Stroke Volume Equation for Impedance Cardiography. Medical and Biological Engineering and Computing, 43(4), 443-450. https://doi.org/10.1007/BF02344724

26.Chabchoub, S.,Mansouri, S., \& Salah, R.B. (2016). Impedance cardiography signal denoising using discrete wavelet transform. Australasian physical \& engineering science in medicine, 39(3), 655-663. Available at: DOI 10.1007/s13246-016-0460-z. https://doi.org/10.1007/s13246-016-0460zPMid:27376722

27.Lababidi Z, Ehmke DA, Durnin RE, Leaverton PE, Lauer RM (1970). The first derivative thoracic impedance cardiogram, American Heart Association. Circulation 41:651-658 https://doi.org/10.1161/01.CIR.41.4.651PMid:5437409

28.Pan, J., Tompkins, W.J. (1985). A real-time QRS detection algorithm. IEEE Transactions on Biomedical Engineering,(3):230-236. https://doi.org/10.1109/TBME.1985.325532PMid:3997178 29.Ramos, P.M., \& Serra, A. C. (2008). Impedance measurement with sine-fitting algorithms implemented in a DSP portable device. IEEE Transactions on instrumentation and measurement,57(1), 197-204 https://doi.org/10.1109/TIM.2007.908276

30.Pinheiro, E., Postolache, O.,\& Girao, P. (2011). Method for segmentation of cardiac signals based on four parameter sine fitting. In EUROCON-International Conference on Computer as a Tool (EUROCON ${ }^{\circ}, 2011$ IEEE(pp. 1-4). IEEE. https://doi.org/10.1109/EUROCON.2011.5929306 
31.Pinheiro,E.C., Postolache, O.A. \&Girao, P.S. (2010). Automatic wavelet detrending benefits to the analysis of cardiac signals acquired in a moving wheelchair. In engineering in Medicine and biology Society (EMBC), 2010 Annual International Conference of the IEEE, pp.602-605).IEEE. https://doi.org/10.1109/IEMBS.2010.5626646PMid:21096105

32.Pinheiro,E.,Postolache,O., \& Girao,P.(2010). Theory and developments in an unobtrusive cardiovascular system representation: Ballistocardiography. The Open Biomedical Engineering Journal, 4,201. https://doi.org/10.2174/1874120701004010201PMid:21673836 PMCid:PMC3111731

33.Zhu, X.,Chen,W.,Nemoto,T.,Kanemitsu,Y.,Kitamura,K.I.,Yamakoshi,K.I., \&Wei, D. (2006). Real-time monitoring of respiration rhythm and pulse rate during sleep. IEEE transactions on biomedical $\quad$ engineering, $53(12)$, 2553-2563. https://doi.org/10.1109/TBME.2006.884641PMid:17153213

34.Shin, J.H.,Choi,B.H.,Lim,Y.G.,Jeong,D.U. \&Park, K.S. (2008). Automatic ballistocardiogram (BCG) beat detection using a template matching approach. In Engineering in Medicine and Biology Society,

2008. EMBS 2008. 30th Annual International Conference of the IEEE (pp.1144-1146). IEEE. https://doi.org/10.1109/IEMBS.2008.4649363PMid:19162866

35.Postolache, O.,Girao, P.S.,Postolache, G., \& Pereira, M.(2007). Vital signs monitoring system based on emfi sensors wavelet analysis. In instrumentation and Measurement Technology Conference Proceeding, 2007. IMTC 2007. IEEE, pp. 1-4).IEEE. https://doi.org/10.1109/IMTC.2007.378999

36.Ermishkin, V. V., Kolesnikov, V.A., Lukoshkova, E.V., \&Sonina, R. S (2013). Simulation of 'pathologic'changes in ICG waveforms resulting from superposition of the 'preejection' and ejection waves induced by left ventricular contraction. In Journal of Physics: Conference Series(Vol. 434, No. 1, p.012007). IOP Publishing. https://doi.org/10.1088/1742-6596/434/1/012007

37.Addison PS (2005) Wavelet transforms and the ECG: A review. PhysiolMeas 26:R155-R199 https://doi.org/10.1088/0967-3334/26/5/R01

38.Cohen, L. (1989). Time-frequency distributions-A review. Proceedings of the IEEE, 77(7):941-981. https://doi.org/10.1109/5.30749

39.Luo,J., Ying, K., He, P., Bai, J. (2005). Properties of Savitzky-Golay digital differentiators. Digit Signal Processing, 15(2) 122-136. https://doi.org/10.1016/j.dsp.2004.09.008

40.Pandey,V.K., Pandey, P.C., Burkule, N.J., \&Subramanyan, L.R. (2011). Adaptive filtering for suppression of respiratory artifact in impedance cardiography. In Engineering in Medicine and Biology Society, EMBC 2011 Annual International Conference of the IEEE (pp.7932-7936). IEEE. https://doi.org/10.1109/IEMBS.2011.6091956PMid:22256180

41.Hu, X., Chen, X., Ren, R., Zhou, B., Qian, Y., Li, H., Xia, S. (2014). Adaptive filtering and characteristics extraction for impedance cardiography. Journal of Fiber bioengineering and Informatics, 7(1),81-90.

42.Pandey, V.K., Pandey, P.C. (2007). Wavelet based cancellation of respiratory artifacts in impedance cardiography. In Digital signal Proceedings, 2007 15th international conference on (pp.191-194).IEEE. https://doi.org/10.1109/ICDSP.2007.4288551

43.Pandey, V.K., Pandey, P.C. (2009). Wavelet based denoising for suppression of motion artifacts in impedance cardiography. In: Proceedings of the international symposium on emerging areas in biotechnology \& bioengineering. Mumbai.

44.Salah, R.B., Alhadidi, T., Mansouri, S. \& Naouar, M. (2015). A new method for cardiac diseases diagnosis. Advances in bioscience and biotechnology, 6(04), 311. https://doi.org/10.4236/abb.2015.64030

45.Chabchoub, S., Mansouri,S., \& Salah, R. B. (2017). Detection of valvular heart diseases using impedance cardiograpgy ICG. Biocybernetics and Biomedical Engineering. Available at: https://doi.org/10.1016/j.bbe.2017.12.002. https://doi.org/10.1016/j.bbe.2017.12.002

46.Khraim, F., Pike, R., Williams, J. (2014) Using non invasive impedance cardiography to assess cardiac hemodynamic measures of persons with heart failure. Canadian Journal of Cardiology,30(10)S371. https://doi.org/10.1016/j.cjca.2014.07.708

47.Packer, M., Abraham, W.T., Mehra, M.R., Yancy,C.W., Lawless, C.E., Mitchell J.E., Pina, I.L. (2006). Utility of impedance cardiography for the identification of short-term risk of clinical decompensation in stable patients with chronic heart failure. Journal of the American College of Cardiology, 47(11),2245-2252. https://doi.org/10.1016/j.jacc.2005.12.071PMid:16750691

48.Chen, S.J., Gong, Z., Duan, Q.L. (2014). Evaluation of heart function with impedance cardiography in acute myocardial infarction patients. International journal of clinical and experimental medicine, 7(3),719. PMid:24753769 PMCid:PMC3992414 
49.Chabchoub, S., Mansouri, S. \& Salah R.B. (2016).Diagnosis of mitral insufficiency using impedance cardiography technique ICG. Journal of Electrical Bioimpedance, 7(1),28-34. https://doi.org/10.5617/jeb.2872

50.Bogaard, H.J., Woltjer, H.H., Postmus, P.E.,\& de Vries, P.M.J.M. (1997). Assessment of the Haemodynamic Response to Exercise by Means of Electrical Impedance Cardiography: Method, Validation and Clinical Applications. Physiological Measurement, 18(2),95. https://doi.org/10.1088/0967-3334/18/2/001PMid:9183804

51.Jansen, J.R.C.(1995).The thermodilution method for the clinical assessment of cardiac output. Intensive Care Medicine, 21(8),691-697. https://doi.org/10.1007/BF01711553PMid:8522677

52.Espersen,K., Jensen, E.W., Rosenborg, D., Thomsen, J.K., Eliasen, K., Olsen, N.V.,\&Kanstrup, I.L.(1995). Comparison of cardiac output measurement techniques: thermodilution, Doppler, CO2rebreathing and the direct Fick method. Acta Anaesthesiologica, Scandinavica,39(2),245-251. https://doi.org/10.1111/j.1399-6576.1995.tb04051.xPMid:7793193

53.Sharma,V, Singh, A., Kansara, B. \&Karlekar, A. (2011).Comparison of transthoracic electrical Bioimpedance cardiac output measurement with thermodilution method in post coronary artery bypass graft patients. Annals of cardiac anaesthesia,14(2),104. https://doi.org/10.4103/09719784.81564PMid:21636930

54.Barde, P., Bhatnagar, A., Narang,R.,\& Deepak, K.K. (2012).Comparison of non-invasive cardiac output measurement using Indigenous impedance cardiography with invasive Fick method. International Journal of Biomedical Research,3(11).https://doi.org/10.7439/ijbar.v3i11.816

55.Cotter, G., Moshkovitz, Y., Kaluski,E.,Cohen,A.J.,Miller, H., Goor, D., \&Vred, Z. (2004). Accurate, noninvasive continuous monitoring of cardiac output by whole-body electrical bioimpedance. Chest, 125(4),1431-40. https://doi.org/10.1378/chest.125.4.1431PMid:15078756

56.Belardinelli, R., Ciampani, N., Costantini, C.,Blandini, A.,\&Purcaro, A.(1996). Comparison of impedance cardiography with thermodilution and direct Fick methods for noninvasive measurement of stroke volume and cardiac output during incremental exercise in patients with ischemic cardiomyopathy. The American Journal of Cardiology,77(15),1293-1301. https://doi.org/10.1016/S0002-9149(97)89153-9.

57.Yung, G.L., Fedullo, P.F., Kinninger, K., Johnson, W. \&Channick, R.N. (2004). Comparison of impedance cardiography to direct Fick and thermodilution cardiac output determination in pulmonary arterial hypertension. Congest Heart Failure,10(s2),7-10. https://doi.org/10.1111/j.15275299.2004.03406.x

58.DeMarzo, A.P., Lang, R.M. (1996).A New Algorithm for Improved Detection of Aortic Valve Opening by Impedance Cardiography. In Computers in Cardiology ,1996 (pp. 373-376). IEEE. https://doi.org/10.1109/CIC.1996.542551

59.Funk, D.J., Moretti, E.W., \& Gan, T.J. (2009). Minimally invasive cardiac output monitoring in the perioperative setting. Anesthesia\& Analgesia,108(3),887-897. https://doi.org/10.1213/ane.0b013e31818ffd99PMid:19224798

60.Kubiček, W. G., Kottke, J., Ramos, M. U., Patterson, R.P., Witsoe, D.A., Labree,J.W. \&Garamela, J.T.(1974).The Minnesota impedance cardiograph-theory and applications. In BioMedical Engineering.

61.Allen, M.T., Fahrenberg, J., Kelsey, R.M., Lovallo, W.R. \&Doornen, L.J.(1990).Methodological guidelines for impedance cardiography. Psychophysiology, 27(1), 1-23 https://doi.org/10.1111/j.1469-8986.1990.tb02171.xPMid:2187214

62.Lozano, D. L., Norman, G., Knox, D.,Wood,B.L.,Miller, B.D., Emery, C.F.,\&Berntson, G. G. (2007).Where to $B$ in dZ/dt.Psychophysiology,44(1),113-119.Available at: https://doi.org/10.1111/j.1469-8986.2006.00468.X

63.Ono T, Miyamura M, Yasuda Y., Ito,T., Saito,T., Ishiguro, T. \&Yambe, T.(2004). Beat-to-beat evaluation of systolic time intervals during bicycle excercise using impedance. Tohoku J.EXp.Med,203,17-29.Available at: https://doi.org/10.1620/tjem.203.17 